\title{
Adaptation and validation of the Portuguese version of the regulation of eating behavior scale (REBSp)
}

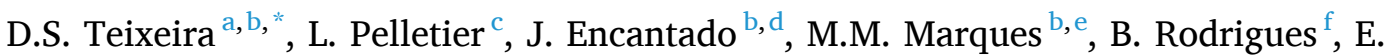 \\ V. Carraça ${ }^{a, b}$

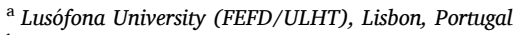 \\ ${ }^{\mathrm{b}}$ Center for the Study of Human Performance (CIPER), Faculdade de Motricidade Humana, Universidade de Lisboa, Lisbon, Portugal \\ ${ }^{\mathrm{c} S}$ School of Psychology, University of Ottawa, Ottawa, Canada \\ ${ }^{\mathrm{d}}$ APPsyCI - Applied Psychology Research Center Capabilities \& Inclusion, ISPA - University Institute, Portugal \\ ${ }^{\mathrm{e}}$ ADAPT Research Centre and Trinity Centre for Practice \& Health Care Innovation, Trinity College Dublin, Dublin, Ireland \\ ${ }^{\mathrm{f}}$ Research Centre in Physical Activity, Health and Leisure, Faculty of Sport, University of Porto, Portugal
}

\section{A R T I C L E I N F O}

\section{Keywords:}

Eating regulation

Self-determination theory

Motivation

Gender invariance

\begin{abstract}
A B S T R A C T
The aim of present study was two-fold: i) to translate and adapt the Regulation of Eating Behavior Scale to Portuguese (REBSp), and ii) to analyze its psychometrics properties (factorial validity with gender invariance analyses, reliability and construct validity). The study sample was composed by 471 Portuguese participants $(68.4 \%$ females) with a mean age of 30.5 years $(S D=11.2)$. Structural equation modeling was used to verify the psychometric properties of the scale using SPSS v. 23.0 and AMOS 24.0 software. The analysis showed that the Portuguese 24-item scale presented a good fit, achieving good reliability and convergent validity. Some issues arose with discriminant validity within autonomous and controlled regulations, discussed in light of the simplex pattern expected by self-determination theory literature. Additionally, the scale presented concurrent validity and evidence of gender measurement invariance. Latent mean analysis between genders showed that women presented higher means for intrinsic motivation and integrated regulation when compared to men. In conclusion, analyses suggest that the 24-item Portuguese version of REBS can be used safely to assess the eating regulation in both genders.
\end{abstract}

\section{Introduction}

There is a considerable amount of research showing that the adoption of inadequate lifestyle behaviors, such as unhealthy eating patterns or lack of physical activity, is associated with increased health risks (Katzmarzyk et al., 2019). These risks include overweight and obesity, type 2 diabetes (Stein \& Colditz, 2004), cardiovascular diseases (Carter, Hartman, Holder, Thijseen, \& Hopkins, 2017), and cancer (Calle, Rodriguez, Walker-Thurmond, \& Thun, 2003). Specifically concerning people's eating behaviors, the current food environment facilitates the access to highly processed foods that are energy dense, which may contribute to the adoption and maintenance of unhealthy eating patterns and ultimately result in these health problems (Carrol et al., 2018; Giskes, van Lenthe, Avendano-Pabon, \& Brug, 2011; Wansink \& Sobal, 2007). In spite of this, the presence of environmental cues to eat food that is unhealthy do not seem to affect all people in the same way, considering that some people seem to be able to adopt and maintain healthy eating patterns. Research grounded in self-determination theory (Ryan \& Deci, 2017) has suggested that the type of motivations underlying the regulation of eating behavior may help to sustain either healthy or unhealthy eating habits, and thus one's vulnerability to the obesogenic environment (Ng et al., 2012; Pelletier, \& Dion, 2007; Pelletier, Dion, Slovinec-D'Angelo, \& Reid, 2004; Pelletier, Guertin, Pope, \& Rocchi, 2016; Rodrigues, Teixeira, Cid, \& Monteiro, 2019).

\subsection{Motivation from the perspective of self-determination theory}

Self-determination theory (SDT) is a prominent theory of human motivation that provides a broad understanding of the motivational dynamics underlying the regulation of behavior in different life domains (Ryan \& Deci, 2017). A core concept in SDT is that individuals go through a natural process of internalization in which they assimilate and

\footnotetext{
* Corresponding author. Lusófona University (FEFD/ULHT), Campo Grande, 376, Lisboa, Portugal.

E-mail address: diogo.teixeira@ulusofona.pt (D.S. Teixeira).
} 
attempt to transform social norms and demands into personally endorsed values and self-regulations. According to SDT, the regulation of behavior can be differentiated along a continuum of self-determination ranging from self-determined or autonomous forms of behavioral regulation (i.e., identification, integration, and intrinsic motivation) to non-self-determined or controlled forms of behavioral regulation (i.e., amotivation, external and introjected regulations) (Ryan \& Deci, 2017). Autonomous motivation reflects self-endorsed reasons for engaging in a certain behavior or pursuing a particular goal. Individuals acting for autonomous reasons experience their actions as freely chosen and consistent with their genuine sense of self, and feel that they are the origin of their actions. Recent studies reported that autonomous motivation is associated with better indicators of physical and mental health, sustained adherence to health behavior, and higher levels of enjoyment, satisfaction, and intention to continue physical activity programs (Rodrigues, Teixeira, Neiva, Cid, \& Monteiro, 2020; Silva et al., 2017). In contrast, when controlled motivation prevails, individuals feel less in control, constrained, and somewhat forced to attain a goal that is not congruent with their interests, deeper values or beliefs. Controlled motivation is often associated with poorer long-term adherence to some health behaviors, lack of persistence and lack of mental flexibility to cope with difficulties when trying to achieve a goal (Ryan \& Deci, 2017). Consequently, SDT-based research highlights the negative effects of controlled regulation on health-related behaviors such as unhealthy eating patterns, poorer mental health and reduced wellbeing (e.g., depression).

Specifically, in the eating domain, controlled motivations to eat have been associated with unhealthy eating behaviors, greater concerns about the quantity of ingested food, and poorer psychological functioning (Carraça, Leong, \& Horwath, 2019; Pelletier et al., 2004). In contrast, autonomous motivations to regulate eating behaviors are positively associated with markers of healthy eating behaviors, greater interest on food quality rather than quantity, and better psychological adjustment (Carraça et al., 2019; Pelletier et al., 2004, 2007).

\subsection{The Regulation of Eating Behavior Scale (REBS)}

Within the SDT framework, the Regulation of Eating Behavior Scale (REBS; Pelletier et al., 2004) is a valid multidimensional and psychometrically sound instrument developed to specifically explore the motivational dynamics underlying eating behavior regulation. The REBS is an instrument that has been widely used to evaluate the different behavioral regulatory styles proposed by SDT in the eating domain (e.g., Bégin, Fecteau, Bédard, Senécal, \& Ratté, 2018; Guertin, Pelletier, \& Pope, 2020; Guertin, Pelletier, Émond, \& Lalande, 2017; Hamilton, Hoffman, Arsiwalla, Volpe, \& Gropper, 2018; Pelletier et al., 2016).

The six-factor structure of the original REBS (i.e., SDT eating behavior regulations), corresponding to the six types of regulations proposed by SDT, was supported by both an Exploratory Factorial Analysis (EFA) and a Confirmatory Factor Analysis (CFA). Overall, the analysis provided information on the psychometric properties of the scale, revealing a good fit to the proposed model, a good internal consistency (Cronbach alpha ranged between 0.77 and 0.90), and support for the construct validity of the scale. Additionally, the REBS was tested for inter-constructs' correlation patterns (i.e., verification of the simplex pattern) and convergent validity constructs (e.g., BULIT-R; CES-D).

Since its original creation, the REBS has been the object of some additional research to examine its psychometric properties. Considering that the original scale was developed with a sample exclusively composed of women, a re-examination of the scale was made by Hamilton et al. (2018), using a mixed-gender sample of 535 Americans. Results supported the scale structure, validity, reliability and, through multi-groups analysis, provided evidence of measurement invariance between gender, further supporting the scale use with both men and women.

The REBS has been widely used in research on eating regulation and there is considerable evidence of its reliability to assess eating behavior motivational processes and predict more or less favorable eating outcomes (Kato, Iwanaga, Roth, Hamasaki, \& Greimel, 2013; Pelletier et al., 2004; Pelletier \& Dion 2007; Román, Rigó, Kato, Horváth, \& Urbán, 2020). For instance, seeking to eat in a healthier way to improve one's appearance rather than to improve one's health may predispose an individual to engage in more extreme dieting strategies and disordered eating behaviors (Putterman \& Linden, 2004), which may in turn undermine successful weight management. Therefore, identifying more robust determinants of autonomous motivations to regulate eating could contribute to help people sticking to healthy eating habits more effectively in the long-term. This scale stands as an important tool for researchers interested in a deeper understanding of eating behavior regulation, which is particularly important in Portugal where overweight and obesity rates are already above $50 \%$ in the adult population (Oliveira et al., 2018). However, no study so far has examined REBS psychometric properties in a Portuguese population. Therefore, the present study objectives were two-fold: i) to translate and adapt the Regulation of Eating Behavior Scale to Portuguese language (REBSp), and ii) to analyze its psychometrics properties (factorial validity with gender invariance analyses, reliability and construct validity) with a sample of Portuguese speaking participants.

\section{Methods}

\subsection{Data collection and translation}

This study involved the completion of an online battery of psychometric questionnaires between January 2017 and December 2018. To be included, participants had to be adults ( $\geq 18$ years of age) and speak/ understand the Portuguese language. No other inclusion criteria were specified. This research was conducted according to the Helsinki declaration and its latter amendments, and the Lusófona University Scientific Board, acting as the ethics committee, approved this study (n. ${ }^{\circ}$ 1/2014-2015).

The REBS original items and instructions were translated to Portuguese and back-translated to English by a panel of psychologists and eating behavior specialists, following Brislin (1970) recommendations. When in disagreement, an external specialist participated in the discussion to obtain consensus. Recruitment was conducted through online channels (e.g., facebook and email). Data was anonymously collected through Google Forms online platform and Qualtrics ${ }^{\mathrm{TM}}$ survey platform to anyone willingly to participate in the study. Before completing the questionnaires, participants were required to provide their informed consent to participate in this study, were informed about the estimated time of completion and that they were free to interrupt or cease participation at any time and at no cost.

\subsection{Participants}

Data was collected from 471 participants (68.4\% females) with a $\mathrm{M}$ age $=30.5$ ( $\mathrm{SD}=11.2$ ) that filled voluntarily two independent surveys in a study designed to investigate healthy lifestyle behaviors (physical activity and eating behavior) and their interaction mechanisms at the motivational level. The study was broadcast through electronic mailing lists and common social networks like Facebook. Due to some technical issues, part of the data from 171 participants (i.e., some demographics and BREQ) was lost. Regarding the full information of the 300 participants, $71 \%$ were female, $61 \%$ were single, $78 \%$ were highly educated (i. e., having a degree or higher), $71 \%$ were currently employed, and $71 \%$ performed $\geq 150$ min per week of moderate-vigorous PA (354.4 \pm $332.8 \mathrm{~min} /$ week). 


\subsection{Measures}

\subsubsection{Regulation of Eating Behavior Scale (Pelletier et al., 2004)}

Like the REBS English the Portuguese version of the scale is comprised of 24-item representing the six subscales corresponding to the behavioral regulations postulated by SDT (Ryan \& Deci, 2017). The stem asks the participants to indicate why they regulate their eating behavior and then to indicate the extent to which the items that follow correspond to the reasons they do so by rating each item using a 7-point Likert scale (1 - 'Does not correspond at all'; to 7 - 'Corresponds exactly'). For example, "I don't really know. I truly have the impression that I'm wasting my time trying to regulate my eating behaviors", represents a question regarding amotivation; "Other people close to me will be upset if I don't", expresses external regulation; "I would feel ashamed of myself if I was not eating healthy", represents introjected regulation; "It is a good idea to try to regulate my eating behaviors" depicts identified regulation; "Eating healthy is part of the way I have chosen to live my life", represents integrated regulation; and "I take pleasure in fixing healthy meals" represents intrinsic motivation.

\subsubsection{Intuitive eating scale 2 (Tylka \& Diest, 2013)}

This scale is a 23-item used to access individuals' tendency to follow their hunger and satiety cues related to eating. A Portuguese version was obtained following the translation procedures recommended by Brislin (1970, 1980). The instrument has four dimensions, namely: Eating for Physical Rather than Emotional Reasons (EPR - 8 items), Unconditional Permission to Eat (UPE - 6 items), Reliance on Hunger and Satiety Cues (RHSC - 6 items), and Body-Food Choice Congruence (BFCC - 3 items). This instrument was used to examine concurrent validity of REBS with eating related cues and is answered using a five-point Likert scale (1 'Strongly disagree'; 5 - 'Strongly agree').

\subsubsection{Behavioral regulation exercise questionnaire 3}

The Portuguese version of the behavioral regulations for exercise questionnaire (BREQ-3p; Cid et al., 2018) is based on the BREQ-2 developed by Markland and Ingledew (1997) and the Integrated Scale made by Wilson et al. (2006). It was used to examine the concurrent validity of REBSp. The BREQ-3p is an 18-item scale that corresponds to the 6 dimensions postulated by SDT. The scale is used to assess behavioral regulation in physical exercise (amotivation, external, introjected, identified and integrated regulations, and intrinsic motivation), and it is answered using a five-point Likert scale ( 0 - Not true to me; 4 - Usually true to me). This scale was assessed only in 300 of the 471 participants.

\subsection{Procedures}

\subsubsection{Data analysis}

In order to test the factorial validity of the REBSp, a confirmatory factor analysis (CFA) was conducted as it is considered one of the most appropriate methods for examining the validity of a scale built on a strong theoretical framework. Because the original REBS was developed to assess motivation using the SDT framework and the items were expected to load onto predetermined theoretical factors, a CFA was justified, and no exploratory factor analysis was conducted. The model was tested using the Maximum Likelihood (ML) estimation. In order to determine whether the model had a good fit, the following fit indices were examined: the Standardized Root Mean Square Residual (SRMR), the Comparative Fit Index (CFI), the Non-Normed Fit Index (NNFI), the Root Mean Square Error of Approximation (RMSEA) and the respective confidence interval $(90 \% \mathrm{CI})$. We used TLI and CFI values $\geq 0.90$ and RMSEA and SRMR $\leq 0.08$ as cut-of values CFA (Byrne, 2016; Hair, Black, Babin, \& Anderson, 2014; Marsh, Hau \& Zen, 2004). Additionally, for final model comparison, the Parsimony Comparative Fit Index (PCFI) and Parsimony Good of Fit Index (PGFI) were used, where indices between 0.60 and 0.80 suggests a good model fit, and indices above 0.80 suggests a very good model fit (Hair et al., 2014).
The convergent validity was examined using the Average Variance Extracted (AVE) to verify if the items were related to the expected factor. Cut-off values above 0.50 cut-off indicated good convergent validity (Hair et al., 2014). The discriminant validity was analysed to understand the level of distinction between factors. This was obtained through the relation of the value of the square of the correlation between factors, where AVE $\geq r^{2}$ (Hair et al., 2014). The reliability of each subscale was assessed by means of internal consistency through Raykov's formula (Raykov, 1997) and the Composite Reliability values (CR $\geq 0.70$ ) (Hair et al., 2014).

Also, we examined the concurrent validity of the scale by performing a correlational analysis between the REBSp and IES2 and BREQ-3p subscales. Regarding the REBSp-IES2, it was expected that the more autonomous regulations would be positively associated with IES2 constructs and, generally, no significant or weak negative associations would emerge between controlled regulations and intuitive eating. Regarding REBSp-BREQ3, it was expected that, overall, moderate correlations between the two scales would be observed and that higher correlations between the same types of motivation from the two scales would be observed.

Multi-group and latent mean analysis invariance were performed to examine the equivalence of the measurement model across genders. This procedure allows the verification of invariance across different groups with different characteristics. Following several authors' recommendations (e.g., Byrne, 2016; Chen, 2007; Cheung \& Rensvold, 2002), invariance criteria is met when the measurement model is adjusted in each group. The following types of invariance were considered: configural invariance (model without constraints), metric invariance (equality of factorial weights), scalar invariance (factorial weights and covariance equals) and residual invariance (factorial weights, covariance and equal measure errors). Thus, $\Delta \chi^{2}$ tests and differences in $\Delta \mathrm{CFI}$ $\leq 0.01$ were examined between the constrained and the unconstrained models (Cheung \& Rensvold, 2002). Additionally, differences in $\triangle$ SRMR $<0.03$ and $\triangle$ RMSEA $<0.015$ for metric invariance, and $\triangle$ SRMR $<0.01$ and $\triangle$ RMSEA $<0.015$ for scalar invariance, were also considered (Byrne, 2016).

Finally, to examine whether measurement invariance criteria were met, a latent mean analysis was performed. Mean and covariance structure analysis for all behavioral regulations allow the testing of differences between genders. The male model was constrained to zero, while the female model was freely estimated for the other group, using $\mathrm{Z}$ scores and $p$ values for each regulation. Effects sizes were calculated in agreement with Kline's (2016) recommendations and Cohen's (1988) $d$ criteria, where effects sizes could be considered (a) trivial (0-0.19), (b) small (0.20-0.49), (c) average (0.50-0.79), or (d) large (greater than or equal to 0.80 ).

All analyses were developed using SPSS v. 23.0 (Armonk, NY, USA) and Amos v. 23.0 (Meadville, PA, USA).

\section{Results}

Preliminary analysis reported no missing values. Six univariate $(\mathrm{z}>$ 3.00 ) and multivariate (Mahalanobis distance $=\mathrm{p} 1<0.001$; $\mathrm{p} 2<$ 0.001 ) outliers were detected and removed from the data for the following analysis (Byrne, 2016). Participants used the full range of the scale (1-7) and presented higher mean scores for the autonomous regulation constructs (ranging from 5.30 to 6.05), and lower scores for the controlled regulation (ranging from 3.61 to 4.35 ) and amotivation (ranging from 3.53 to 3.57 ) constructs (Table 1). As seen in Table 1, the skewness and kurtosis values indicate that the responses had generally a normal univariate distribution to the data (normality accepted value of skewness and kurtosis ranging from -2 to +2 and -7 to +7 , respectively). Additionally, Mardia's coefficient for multivariate kurtosis was superior to the expected value for normality assumption ( $>5.0$ ) (Byrne, 2016), and Bollen-Stine bootstrap with 2000 samples was used for subsequent analysis (Nevitt \& Hancock, 2001). 
Table 1

Descriptive analysis of the answers to the items on the REBS for the Portuguese sample.

\begin{tabular}{lllll}
\hline & Skewness & z-value & Kurtosis & z-value \\
\hline Item 1 (Integrated) & -1.34 & -11.90 & 1.25 & 5.53 \\
Item 2 (Intrinsic) & -.89 & -7.92 & -.11 & -.48 \\
Item 3 (External) & -.36 & -3.23 & -.98 & -4.35 \\
Item 4 (Intrinsic) & -.91 & -8.09 & -.10 & -.42 \\
Item 5 (Identified) & -1.49 & -13.24 & 2.11 & 9.33 \\
Item 6 (Amotivation) & -.29 & -2.61 & -1.32 & -5.86 \\
Item 7 (Introjected) & -.11 & -.98 & -1.01 & -4.47 \\
Item 8 (Introjected) & -.31 & -2.72 & -1.01 & -4.45 \\
Item 9 (External) & -.26 & -2.27 & -1.16 & -5.12 \\
Item 10 (Identified) & -1.5 & -12.94 & 1.85 & 8.18 \\
Item 11 (Intrinsic) & -1.35 & -11.95 & 1.40 & 6.20 \\
Item 12 (Introjected) & -.18 & -1.63 & -1.05 & -4.65 \\
Item 13 (External) & -.25 & -2.23 & -1.22 & -5.40 \\
Item 14 (Amotivation) & -.39 & -3.42 & -1.47 & -6.52 \\
Item 15 (External) & -.30 & -2.66 & -1.19 & -5.25 \\
Item 16 (Amotivation) & -.32 & -2.84 & -1.35 & -5.97 \\
Item 17 (Integrated) & -1.07 & -9.49 & .33 & 1.45 \\
Item 18 (Introjected) & -.29 & -2.58 & -1.14 & -5.04 \\
Item 19 (Amotivation) & -.28 & -2.44 & -1.32 & -5.85 \\
Item 20 (Integrated) & -.89 & -7.84 & -.19 & -.86 \\
Item 21 (Integrated) & -1.23 & -10.88 & .74 & 3.28 \\
Item 22 (Identified) & -1.70 & -15.08 & 2.91 & 12.90 \\
Item 23 (Identified) & -1.64 & -14.56 & 2.51 & 11.14 \\
Item 24 (Intrinsic) & -.924 & -8.19 & .046 & .20 \\
\hline
\end{tabular}

The goodness of fit indices for the CFA analysis (six factors and 24 items) are presented in Table 2 and the coefficients for the full model are presented in Fig. 1. The model fitted the data well and was in line with predefined cut-off values (Hair et al., 2014).

Construct validity and reliability coefficients are presented in Table 3 . The composite reliability ( $C R \geq 0.70$ ) and convergent validity (AVE $\geq 0.50$ ) coefficients presented are adjusted values. Some issues emerged regarding the discriminant validity (IM-INTEGR; INTEGIDENT; INTROJ-EXT; EXT-AMOT), because the squared value of the correlations $\left(r^{2}\right)$ was higher than the AVE (Hair et al., 2014).

As seen in Table 2, both gender 24-item models presented good fit indices, justifying a measurement invariance analysis. Models respecification suggests support for invariance between these two groups, showing that a) the same number of factors was present in both groups and remained associated with the same items (configural invariance), b) the REBS' factors had a similar understanding in both groups (measurement invariance) and c) latent and observable means were valid in both groups when means were compared (scale invariance), and d) comparison between observable items was supported (residual invariance). After testing, only residual invariance was not met, surpassing the predefined $\Delta$ CFI cut-off value $(0.012>.010)$ (Cheung \& Rensvold, 2002) (Table 4).

Given that the measurement invariance represents a good fit, latent means analyses were performed to test group differences (male vs. female) (Table 5). Intrinsic motivation and integrated regulation were significantly higher in females than in males (intrinsic motivation; $\mathrm{Z}=$ $3.795, p<.001$; integrated regulation; $\mathrm{Z}=2.175, p=.03$ ).

To assess concurrent validity, correlational analysis between the
REBSp, IES2, and BREQ-3p were conducted and reported in Table 6. Associations with BMI (by gender) are also presented. Regarding the correlations between the REBSp subscales and the dimensions of the IES2, the autonomous regulations were positively correlated with the 4 dimensions of the IES2, while the controlled regulations were negatively, or not significantly related with those constructs. Concerning REBSp and BREQ-3p analysis, the results show that 4 of the 6 specific types of regulations for the REBSp were more strongly correlated with the same types of motivation for the BREQ-3p, while the other 2 (intrinsic motivation and amotivation) showed higher correlations with different regulations across scales. Finally, no significant associations emerged between the REBSp/BMI testing (except BMI Female with REBSp Integrated regulation).

\section{Discussion}

The aim of the present study was to adapt the Regulation of Eating Behaviour Scale for the Portuguese population (REBSp) and to validate this version by testing its factorial structure and the psychometric properties. Additionally, measurement invariance procedures were done in order to examine scale assumptions between genders.

The results of the present study provide support for the validity of the Portuguese version of the REBS in the Portuguese population, in general and across genders. In agreement with previous studies (Hamilton et al., 2018; Pelletier et al., 2004), the 24 items followed the 6 -factor structure of the original scale, as showed by the fit indices, internal consistency of the subscales and convergent validity of the scale.

However, some issues were found regarding the discriminant validity of the scale. Correlations among the types of autonomous regulations (IM-INTEGR; INTEG-IDENT) and types of controlled regulations/ amotivation (INTRJ-EXT; EXT-AMOT) were high, which suggests that some subscales shared similarities with each other. The SDT behavioral regulations are structured in a simplex pattern, meaning that throughout the continuum, it is expected to exist construct similarities and possible overlaps in adjacent regulations, that tend to disappear in more distant regulations (Ryan \& Deci, 2017). In fact, similar problems have been reported in other scales grounded in SDT, as is the case, for example, of sport (e.g., Lonsdale, Sabiston, Taylor, \& Ntoumanis, 2011; Pelletier et al., 1995). These results differ to some extent from the results reported by Pelletier et al. (2004) and it is not entirely clear why this occurred. Future research should further examine the discriminant validity of the scale with more heterogeneous, culturally diverse, samples to determine if the results that were observed are specific to our sample.

In agreement with Hamilton et al. (2018), our results also supported the gender measurement invariance of the scale. More specifically, the models for both genders showed a good fit, and the multi-group analysis showed that configural, measurement and scale invariance criterion were met (Byrne, 2016). Residual invariance in this sample was not met. However, this parameter has been considered optional in social sciences, due to the fact that not achieving a $\Delta \mathrm{CFI}<0.01$ may not implicate the absence of scale measurement invariance in these settings (Byrne, 2016; Cheung \& Rensvold, 2010).

Latent mean analysis procedures showed that intrinsic motivation and integrated regulation were significantly higher in women. These

Table 2

Goodness-of-fit indices of RESB models (including other versions).

\begin{tabular}{|c|c|c|c|c|c|c|c|c|c|}
\hline Models & $\chi^{2}$ & df & $\mathrm{p}$ & SRMR & TLI & CFI & RMSEA $90 \%$ CI & PCFI & PGFI \\
\hline 24 items model & 803,400 & 237 & $<.001$ & .057 & .940 & .949 & .071 [.066-.077] & .815 & .689 \\
\hline Pelletier et al. model ${ }^{1}$ & 531.970 & - & $<.001$ & - & - & .920 & $.060[-]$ & .780 & - \\
\hline Hamilton et al. model $^{2}$ & 1078.47 & 474 & $<.001$ & - & - & .930 & $.050[-]$ & .800 & - \\
\hline Male 24 items model & 472.008 & 237 & $<.001$ & .072 & .922 & .933 & $.081[.071-.093]$ & .801 & .627 \\
\hline Female 24 items model & 662.132 & 237 & $<.001$ & .055 & .935 & .945 & $.075[.068-.082]$ & .811 & .672 \\
\hline
\end{tabular}

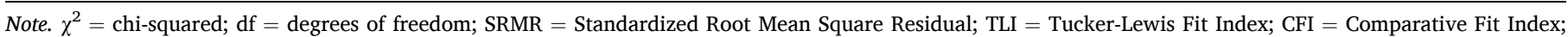

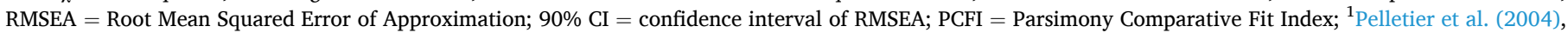
${ }^{2}$ Hamilton et al. (2018). 


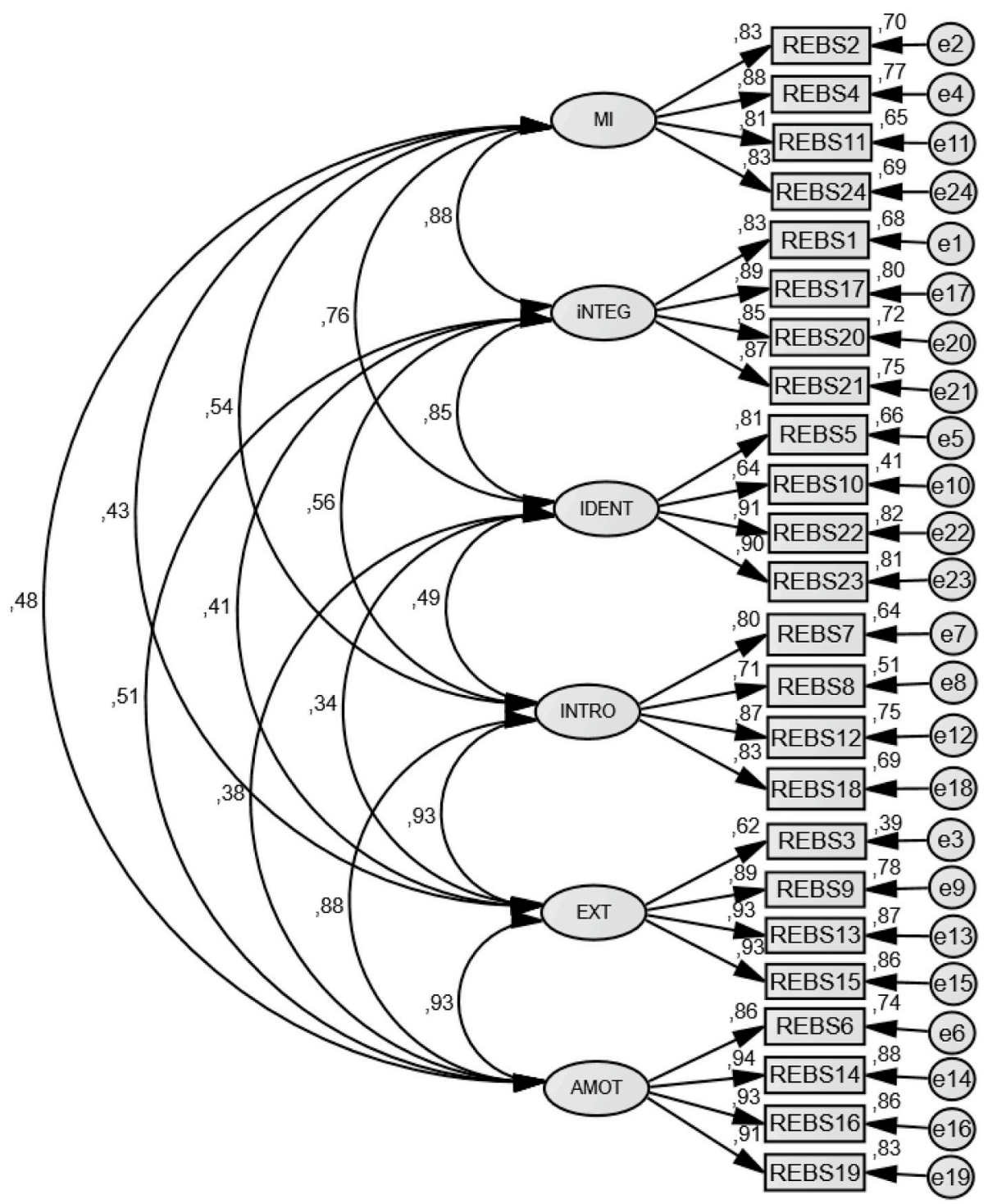

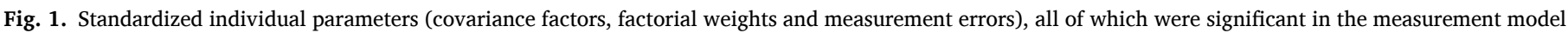
(REBSp - six factors and 24 items).

Table 3

Internal reliability, convergent and discriminant validity, and average variance extracted for the 24 item model.

\begin{tabular}{|c|c|c|c|c|c|c|c|c|}
\hline Factors & CR & AVE & IM & INTEGR & IDENT & INTROJ & EXT & AMOT \\
\hline IM & .904 & .702 & 1 & & & & & \\
\hline INTEGR & .919 & .740 & .769 & 1 & & & & \\
\hline IDENT & .891 & .676 & .573 & .724 & 1 & & & \\
\hline INTROJ & .880 & .647 & .293 & .309 & .238 & 1 & & \\
\hline EXT & .912 & .727 & .185 & .171 & .114 & .863 & 1 & \\
\hline AMOT & .951 & .829 & .233 & .255 & .148 & .781 & .856 & 1 \\
\hline
\end{tabular}

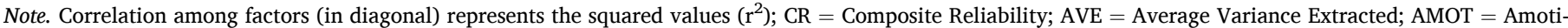

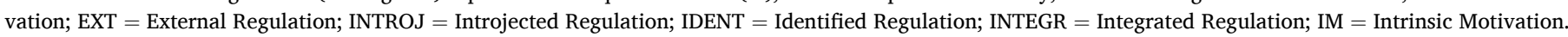

results are similar to the ones reported by Hamilton's et al. (2018) recent psychometric re-evaluation of the REBS. These authors found higher autonomous motivation levels (intrinsic and identified) in women and higher levels of introjected and external regulations as well. Our findings are coherent with prior research showing that women tend to attribute greater value to healthy eating and view food choices as more important for their health (Courtenay, McCreary, \& Merighi, 2002; Wardle et al., 2004). One possible explanation for this may be related to a woman's role in the family context. That is, women are more likely to be responsible for family meal preparation or food shopping than men, and because of that they may be more likely to pay attention to the importance of eating healthy (Fagerli \& Wandel, 1999). Also, the socially constructed gender roles, which are internalized in young age, are likely to explain these gender differences (Courtenay, 2000). This author suggested that males may not be encouraged to know more about health and nutrition, cooking and eating healthily, when compared to females which are encouraged to place higher priority on learning and making healthy food choices (Courtenay, 2000). Differences in internalized 
Table 4

Fit indices for the measurement invariance model of the REBS in the Portuguese sample across gender.

\begin{tabular}{|c|c|c|c|c|c|c|c|c|c|c|c|}
\hline $\mathrm{M}-\mathrm{F}$ & $\chi^{2}$ & df & $\Delta \chi^{2}$ & $\Delta \mathrm{df}$ & $\mathrm{p}$ & CFI & $\Delta \mathrm{CFI}$ & SRMR & $\Delta$ SRMR & RMSEA & $\triangle$ RMSEA \\
\hline Configural Invariance & 1134.553 & 474 & - & - & $<.001$ & .941 & - & .072 & - & .055 & - \\
\hline Measurement Invariance & 1148.676 & 492 & 14.123 & 18 & $<.001$ & .941 & .000 & .072 & .000 & .053 & .002 \\
\hline Scale Invariance & 1207.663 & 513 & 73.110 & 39 & $<.001$ & .938 & .003 & .082 & .010 & .054 & .001 \\
\hline Residual Invariance & 1327.373 & 537 & 192.820 & 63 & $<.001$ & .929 & .012 & .092 & .020 & .056 & .001 \\
\hline
\end{tabular}

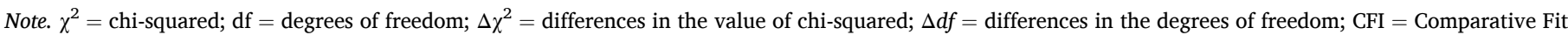
Index; $\Delta \mathrm{CFI}=$ differences in the value of the Comparative Fit Index.

Table 5

Latent mean differences between genders on behavioral constructs.

\begin{tabular}{lllll}
\hline & Difference & $\mathrm{Z}$ & $p$ & $d$ \\
\hline Intrinsic & .569 & 3.795 & $<.001$ & .24 \\
Integrated & .275 & 2.175 & .03 & .38 \\
Identified & .178 & 1.565 & .118 & .13 \\
Introjected & .204 & 1.311 & .190 & .22 \\
External & .013 & .082 & .934 & .02 \\
Amotivation & .144 & .900 & .368 & .13 \\
\hline
\end{tabular}

Note. $\mathrm{Z}=$ test score; $\mathrm{p}=$ sig. value; $d=$ Cohens' effect size.

beliefs about the value of eating according to health recommendations, and in the interest (and potential pleasure) in learning and preparing healthy foods could therefore contribute to explain the observed gender differences in eating regulations.

The concurrent validity of the scale was also examined against two distinct scales, the IES2, measuring eating in response to hunger and satiety cues, and BREQ-3, measuring exercise behavioral regulations. Considering the nature of the REBSp, we expected that a more autonomous motivation to regulate eating would be related with a closer and more reliable interpretation of physical signs of hunger and satiety, and with increased enjoyment of a wide variety of foods, as opposed to strict dieting rules/restrictions or comfort eating (Tylka \& Diest, 2013; Tylka, Calogero, \& Danielsdottir, 2015; Carraça et al., 2019). The results obtained in the present analysis were thus consistent with the expected associations.

Considering the conceptual proximity and close relation between exercise and healthy eating behaviors, which tend to cluster (Andrade et al., 2010; Loprinzi, Smit, \& Mahoney, 2014) and be explained by similar mechanisms (Mata et al., 2009; Annesi \& Marti, 2011; Fleig, Küper, Lippke, Schwarzer, \& Wiedemann, 2015), we expected positive associations between corresponding behavioral regulations across the two life domains. Although, we found some discrepancies for the intrinsic motivation and amotivation subscale, overall results provided support for the concurrent validity of REBSp.

Finally, not all people respond equally to the current food environment, making some individuals more vulnerable to the obesogenic environment than others. That justifies the need to deepen our understanding of the individual factors that could influence one's susceptibility to maladjusted eating patterns. Therefore, the REBSp may be particularly useful for practitioners, as it allows them to identify the reasons underlying individuals' eating regulation. Knowing why one eats in a specific way, or makes certain food choices, can help practitioners promoting more balanced eating behaviors. As shown in prior research (e.g., Pelletier et al., 2004; Carraça et al., 2019), different types of eating motivation (autonomous vs. controlled) are linked to different behavioral and psychological outcomes: autonomous motivations to regulate eating have been associated with healthier eating behaviors and better psychological functioning, while controlled regulations and amotivation are associated to poorer outcomes. In agreement with these results, future research should examine if participants would benefit from conditions that focus on creating need-supportive environments, for instance, by supporting people's autonomy and choice, eliciting personally-relevant goals, avoiding controlling language and external reinforcers, providing structure and offering a rationale for what is being proposed, in a respectful, non-judgmental and empathetic climate (Ryan \& Deci, 2017).

\subsection{Strengths and limitations}

In sum, our results provide evidence for the REBSp use in the Portuguese population. The hypothesized model presented good fit to the data in a large sample and proved to be reliable in both genders. Internal consistency, convergent validity, measurement invariance and concurrent tests offer confidence upon the robustness of our findings. This is especially important considering the high rates of overweight and obesity $(>50 \%)$ in the Portuguese population (Oliveira et al., 2018). Finding reliable and valid tools, which allow the identification of determinants of autonomous (vs. controlled) motivations to regulate eating, could therefore facilitate people's sustained adherence to healthy eating habits and, subsequently, to more successful weight management in the long run. Notwithstanding this, our study had some limitations, and some issues with the discriminant validity of some of the subscales were identified. These issues highlight the need to further evaluate the validity of the scale with more heterogeneous samples of Portuguese participants (e.g., individuals showing more or less dysfunctional eating patterns). Additionally, due to some technical issues, some data were not retrieved from the second independent sample, and the results from some socio-demographic variables and BREQ-3p were only accounted for the first sample collected. Despite confidence of the analysis developed, the data missing in 174 participants could add

Table 6

Correlation analysis of REBSp, IES 2, BREQ-3p and BMI (by gender).

\begin{tabular}{|c|c|c|c|c|c|c|c|c|c|c|c|c|}
\hline \multirow[t]{2}{*}{ REBS } & \multicolumn{4}{|l|}{ IES2 } & \multicolumn{6}{|l|}{ BREQ3 } & \multirow{2}{*}{$\begin{array}{l}\text { BMI }\left(\mathrm{kg} / \mathrm{m}^{2}\right) \\
\text { Male } \\
(\mathrm{M}=22.8 \\
\mathrm{DP}=3.6)\end{array}$} & \multirow{2}{*}{$\begin{array}{l}\text { BMI }\left(\mathrm{kg} / \mathrm{m}^{2}\right) \\
\text { Female } \\
(\mathrm{M}=24.5 \\
\mathrm{DP}=3.4)\end{array}$} \\
\hline & RHSC & EPR & UPE & BFCC & Intrinsic & Integrated & Identified & Introjected & External & Amotivation & & \\
\hline Intrinsic & $.299 * * *$ & $.247 * * *$ & $.342 * * *$ & $.577^{* * *}$ & $.353^{* * *}$ & $.453^{* * *}$ & $.364 * * *$ & $.313 * * *$ & -.075 & -.117 & -.069 & -.093 \\
\hline Integrated & $.247 * * *$ & $.260 * * *$ & $.819 * * *$ & $.654 * * *$ & $.394 * * *$ & $.541 * * *$ & $.494 * * *$ & $.315^{* * *}$ & $-.176^{*}$ & $-.185^{*}$ & -.040 & $-.147 * *$ \\
\hline Identified & $.228^{* * *}$ & $.229 * * *$ & $.733^{* * *}$ & $.610^{* * *}$ & $.200^{* *}$ & $.390 * * *$ & $.498^{* * *}$ & $.286^{* *}$ & -.142 & $-.204 * *$ & .038 & .051 \\
\hline Introjected & -.097 & $-.328^{* * * *}$ & $.168^{* *}$ & .026 & -.126 & .069 & .123 & $.513^{* * *}$ & $.406^{* * *}$ & $.237 * *$ & -.043 & .078 \\
\hline External & -.023 & $-.232 * * *$ & .087 & -.010 & -.093 & -.034 & -.303 & $.307 * * *$ & $.541 * * *$ & $.295^{* * *}$ & -.031 & .053 \\
\hline Amotivation & -.076 & $-.202 * * *$ & $-.183^{* *}$ & $-.275 * * *$ & -.069 & -.009 & $-.151 *$ & .132 & $.456 * * *$ & $.456 * * *$ & -.107 & -.016 \\
\hline
\end{tabular}

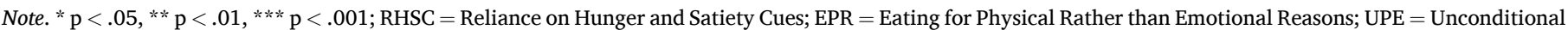
Permission to Eat; BFCC = Body-Food Choice Congruence; BMI = Body Mass Index. 
some additional information of sample heterogeneity and characteristics that could elicit future study directions.

Overall, the present study revealed that the six-factor, 24-item REBSp, had good psychometric properties. The scale can be used in both genders of the Portuguese population for research purposes in the context of eating behavior regulation.

\section{Ethical statement}

This study was performed in accordance with the Declaration of Helsinki and was approved by Lusófona University Scientific Board, acting as the ethics committee. An informed consent was obtained from each voluntary participant before his or her enrolment in the study.

\section{Funding}

Diogo S. Teixeira was partly supported by the Fundação para a Ciência e Tecnologia, under Grant UIDB/00447/2020 to CIPER - Centro Interdisciplinar para o Estudo da Performance Humana (unit 447). Bruno Rodrigues was supported by Fundação para a Ciência e Tecnologia, under Grant FCT/UIDB/00617/2020 to CIAFEL - Research Centre on Physical Activity Health and Leisure (unit 617). Marta M. Marques was funded by a Marie-Sklodowska-Curie Fellowship (Co-fund EDGE programme, grant agreement no. 713567).

\section{Declaration of competing interest}

The authors also declare that they have no known competing financial interests or personal relationships that could have appeared to influence the work reported in this paper.

\section{Appendix A. Supplementary data}

Supplementary data to this article can be found online at https://doi. org/10.1016/j.appet.2020.104957.

\section{References}

Andrade, A. M., Coutinho, S. R., Silva, M. N., Mata, J., Vieira, P. N., Minderico, C. S. et al. (2010). The effect of physical activity on weight loss is mediated by eating selfregulation. Patient Education and Counseling, 79(3), 320-326. https://doi.org/ 10.1016/j.pec.2010.01.006. Epub 2010 Feb 10.

Annesi, J. J., \& Marti, C. N. (2011). Path analysis of exercise treatment-induced changes in psychological factors leading to weight loss. Psychology and Health, 26(8), 1081-1098. https://doi.org/10.1080/08870446.2010.534167

Bégin, C. Fecteau, C. M., Bédard, A., Senécal, C. \& Ratté, C. (2018). Disordered eating behaviors through the lens of self-determination theory. European Journal Psychology, 14(3), 571-580.

Brislin, R. (1970). Back-translation for cross-cultural research. Journal of Cross-Cultural Psychology, 1(3), 187-216. https://doi.org/10.1177/135910457000100301

Brislin, R. (1980). Translation and content analysis of oral and written material. In H. C. Triandis, \& R. W. Brislin (Eds.), Handbook of cross-cultural psychology (pp. 389-444). Boston, MA: Allyn and Bacon.

Byrne, B. (2016). Structural equation modeling with AMOS. Basic concepts, applications, and programming ( $3^{\text {rd }}$ ed.). New York: Taylor \& Francis Group, LLC.

Calle, E. E., Rodriguez, C., Walker-Thurmond, \& Thun, M. J. (2003). Overweight, obesity, and mortality from cancer in a prospectively studied cohort of U.S. adults. New England Journal of Medicine, 24, 1625-1638.

Carraça, E. V., Leong, S. L., \& Horwath, C. (2019). Weight-focused physical activity is associated with poorer eating motivation quality and lower intuitive eating in women. J. Acad. Nutr. Diet, 119(5), 750-759.

Carroll, S. J., Niyonsenga, T., Coffee, N. T., Taylor, A. W., \& Daniel, M. (2018). Associations between local descriptive norms for overweight/obesity and insufficient fruit intake, individual-level diet, and 10-year change in body mass index and glycosylated haemoglobin in an Australian cohort. International Journal of Behavioral Nutrition and Physical Activity, 15(1), 1-16. https://doi.org/10.1186/ s12966-018-0675-3

Carter, S., Hartman, Y., Holder, S., Thijssen, D. H., \& Hopkins, N. D. (2017). Sedentary behavior and cardiovascular disease risk: Mediating mechanisms. Exercise and Sport Sciences Reviews, 45(2), 80-86. https://doi.org/10.1249/JES.0000000000000106

Chen, F. (2007). Sensitivity of goodness of fit indexes to lack of measurement invariance. Structural Equation Modeling, 14(3), 464-504. https://doi.org/10.1080/ 1070551070131834
Cheung, G., \& Rensvold, R. (2002). Evaluating goodness-of-fit indexes for testing measurement invariance. Structural Equation Modeling, 9(2), 233-255. https://doi. org/10.1207/S15328007SEM0902_5chen

Cid, L., Monteiro, D., Teixeira, D., Alves, S., Moutã o, J., Teques, P., ... Palmeira, A. (2018). The Behavioral Regulation in Exercise Questionnaire (BREQ-3) Portuguese version: Evidence of reliability, validity and invariance across gender. Frontiers in Psychology, 9, 1940. https://doi.org/10.3389/fpsyg.2018.01940

Cohen, J. (1988). Statistical power analysis for the behavioral sciences $\left(2^{\text {nd }}\right.$ ed.). Hillsdale, NJ: Lawrence Erlbaum Associates.

Courtenay, W. H. (2000). Engendering health: A social constructionist examination of men's health beliefs and behaviors. Psychology of Men and Masculinity, 1, 4-15. https://doi.org/10.1037/1524-9220.1.1.4

Courtenay, W. H., McCreary, D. R., \& Merighi, J. R. (2002). Gender and ethnic differences in health beliefs and behaviors. Journal of Health Psychology, 7, 219-231. https://doi.org/10.1177/1359105302007003216

Fagerli, R. A., \& Wandel, M. (1999). Gender differences in opinions and practices with regard to a "Healthy Diet". Appetite, 32, 171-190.

Fleig, L., Küper, C., Lippke, S., Schwarzer, R., \& Wiedemann, A. U. (2015). Crossbehavior associations and multiple behavior change: A longitudinal study on physical activity and fruit and vegetable intake. Journal of Health Psychology, 20(5), 525-534, 2015.

Giskes, K., van Lenthe, F., Avendano-Pabon, M., \& Brug, J. (2011). A systematic review of environmental factors and obesogenic dietary intakes among adults: Are we getting closer to understanding obesogenic environments? Obesity Reviews, 12(5), e95-e106.

Guertin, C., Pelletier, L., Émond, C., \& Lalande, G. (2017). Change in physical and psychological health over time in patients with cardiovascular disease: On the benefits of being self-determined, physically active, and eating well. Motivation and Emotion, 41, 294-307.

Guertin, C., Pelletier, L., \& Pope, P. (2020). The validation of the Healthy and Unhealthy Eating Behavior Scale (HUEBS): Examining the interplay between stages of change and motivation and their association with healthy and unhealthy eating behaviors and physical health. Appetite, 144, 104487. https://doi.org/10.1016/j. appet.2019.104487

Hair, J., Black, W., Babin, B., \& Anderson, R. (2014). Multivariate data analysis (7th ed.). Hoboken, NJ: Pearson Educational.

Hamilton, T., Hoffman, J., Arsiwalla, D., Volpe, R., Schmidt, E., \& Gropper, S. (2018). Gender comparisons of young adults' eating behavior regulation: Re-examination of the regulation of eating behavior scale (REBS). Appetite, 126, 80-89. https://doi.org/ 10.1016/j.appet.2018.03.014

Kato, Y., Iwanaga, M., Roth, R., Hamasaki, T., \& Greimel, E. (2013). Psychometric validation of the motivation for healthy eating scale (MHES). Psychology, 4(2), 136-141. https://doi.org/10.4236/psych.2013.42020

Katzmarzyk, P. T., Powell, K. E., Jakicic, J. M., Troiano, R. P., Piercy, K., \& Tennant, B. (2019). Sedentary behavior and health: Update from the 2018 physical activity guidelines advisory committee. Medicine \& Science in Sports \& Exercise, 51(6), 1227-1241. https://doi.org/10.1249/MSS.0000000000001935

Kline, R. (2016). Principles and practice of structural equation modelling ( $3^{\text {rd }}$ ed.). New York, NY: The Guildford Press.

Lonsdale, C., Sabiston, C., Taylor, I., \& Ntoumanis, N. (2011). Measuring student motivation for physical education: Examining the psychometric properties of the perceived locus of causality questionnaire and the situational motivation scale. Psychology of Sport and Exercise, 12(3), 284-292.

Loprinzi, P. D., Smit, E., \& Mahoney, S. (2014). Physical activity and dietary behavior in US adults and their combined influence on health. Mayo Clinic Proceedings, 89(2), 190-198.

Marsh, H., Hau, K., \& Wen, Z. (2004). In search of golden rules: Comment on hypothesis testing approaches to setting cutoff values for fit indexes and dangers in overgeneralizing Hu and Bentler's (1999) findings. Structural Equation Modeling, 11 (3), 320-341. https://doi.org/10.1207/s15328007sem1103_2

Mata, J., Silva, M. N., Vieira, P. N., Carraça, E., Abdrade, A. M., Coutinho, S. R., et al. (2009). Motivational "spill-over" during weight control: Increased self-determination and exercise intrinsic motivation predict eating self-regulation. Health Psychology, 28 (6), 709-716.

Nevitt, J., \& Hancock, G. R. (2001). Performance of bootstrapping approaches to model test statistics and parameter standard error estimation in structural equation modeling. Structural Equation Modeling, 8, 353-377. https://doi.org/10.1207/ S15328007SEM0803_2

Ng, J. Y., Ntoumanis, N., Thøgersen-Ntoumani, C., Deci, E. L., Ryan, R. M., Duda, J. L., \& Williams, G. C. (2012). Self-Determination Theory Applied to Health Contexts: A Meta-Analysis. Perspectives on Psychological Science, 7(4), 325-340. https://doi.org/1 $0.1177 / 1745691612447309$.

Oliveira, A., Araújo, J., Severo, M., Correia, D., Ramos, E., ... Lopes, C. (2018). Prevalence of general and abdominal obesity in Portugal: Comprehensive results from the national food, nutrition and physical activity survey 2015-2016. BMC Public Health, 18, 614. https://doi.org/10.1186/s12889-018-5480-z

Pelletier, L. G., \& Dion, S. C. (2007). An examination of general and specific motivational mechanisms for the relations between body dissatisfaction and eating behaviors. Journal of Social and Clinical Psychology, 26, 303-333.

Pelletier, L. G., Dion, S. C., Slovinec-D'Angelo, M., \& Reid, R. (2004). Why do you regulate what you eat? Relationships between forms of regulation, eating behaviors, sustained dietary behavior change, and psychological adjustment. Motivation and Emotion, 28(3), 245-277. https://doi.org/10.1023/B:MOEM.0000040154.40922.14

Pelletier, L., Guertin, C., Pope, J., \& Rocchi, M. (2016). Homeostasis balance, homeostasis imbalance or distinct motivational processes? Comments on Marks (2015) 'Homeostatic Theory of Obesity. Health Psychology Open, 1-4. https://doi. org/10.1177/2055102915624512 
Pelletier, L. G., Tuson, K., Fortier, M., Vallerand, R., Brikre, N., \& Blais, M. (1995). Toward a new measure of intrinsic motivation, extrinsic motivation, and amotivation in sports: The sport motivation scale (SMS). Journal of Sport \& Exercise Psychology, 17, 35-53.

Putterman, E., \& Linden, W. (2004). Appearance vs health: Does the reason for dieting affect dieting behavior. Journal of Behavioral Medicine, 72(2), 185-204.

Raykov, T. (1997). Estimation of composite reliability for congeneric measures. Applied Psychological Measurement, 21(2), 173-184. https://doi.org/10.1177/ 01466216970212006

Rodrigues, F., Teixeira, D. S., Cid, L., \& Monteiro, D. (2019). Have you been exercising lately? Testing the role of past behavior on exercise adherence. Journal of Health Psychology, 1-12. https://doi.org/10.1177/135910531987824

Rodrigues, F., Teixeira, D., Neiva, H., Cid, L., \& Monteiro, D. (2020). The bright and dark sides of motivation as predictors of enjoyment, intention, and exercise persistence. Scandinavian Journal of Medicine \& Science in Sports, 1-14. https://doi.org/10.1111/ sms. 13617

Román, N., Rigó, A., Kato, Y., Horváth, Z., \& Urbán, R. (2020). Cross-cultural comparison of the motivations for healthy eating: Investigating the validity and invariance of the motivation for healthy eating scale. Psychology and Health. https://doi.org/10.1080/ 08870446.2020 .1773462

Ryan, R., \& Deci, E. (2017). Self-determination theory. Basic psychological needs in motivation, development, and wellness. New York: Guildford Press.
Silva, M. N., Sánchez-Oliva, D., Brunet, J., Williams, G. C., Teixeira, P. J., \& Palmeira, A. L. (2017). What Goes Around Comes Around": Antecedents, Mediators, and Consequences of Controlling vs. Need-Supportive Motivational Strategies Used by Exercise Professionals. Annals of Behavioral Medicine, 51(1). https://doi.org/ 10.1007/s12160-017-9894-0

Stein, C., \& Colditz, G. (2004). The epidemic of obesity. Journal of Clinical Endocrinology \& Metabolism, 86(6), 2522-2525.

Tylka, T. L., Calogero, R. M., \& Danielsdottir, S. (2015). Is intuitive eating the same as flexible dietary control? Their links to each other and well-being could provide an answer. Appetite, 95, 166-175.

Tylka, T. L., \& Diest, A. M. (2013). The Intuitive Eating Scale 2: Item refinement and psychometric evaluation with college women and men. Journal of Counseling Psychology, 60(1), 137-153.

Wansink, B., \& Sobal, J. (2007). Mindless eating: The 200 daily food decisions we overlook. Environment and Behavior, 39(1), 106-123. https://doi.org/10.1177/ 0013916506295573

Wardle, J., Haase, A. M., Steptoe, A., Nillapun, M., Jonwutiwes, K., \& Bellisle, F. (2004). Gender differences in food choice: The contribution of health beliefs and dieting. Annals of Behavioral Medicine, 27, 107-116. https://doi.org/10.1207/ s15324796abm2702 5 